\title{
STUDI POTENSI DAN PELUANG EKOWISATA DI HUTAN DESA TANGKAHEN KECAMATAN BANAMA TINGANG KABUPATEN PULANG PISAU
}

\author{
the study of Potentital and Opportunity of Ecotourism of Tangkahen Village Forest, Banama Tingang \\ Sub District, Pulang Pisau
}

\author{
Yos A. Tangkasiang' \\ Kristanto.V.Baddak ${ }^{2}$ \\ IProdi Kehutanan \\ Fakultas Pertanian \\ Universitas PGRI \\ Palangka Raya \\ 2Prodi Pendidikan \\ Sejarah FKIP \\ Universitas PGRI \\ Palangka Raya
}

\section{Kata Kunci: \\ Ekowisata, Manfaat \\ Ekonomi, Daya \\ Dukung, Konservasi, \\ Pelestarian Lingkungan \\ Keywords: \\ Ecotourism, Economic \\ Benefit, Carrying \\ Capacity, Conservation, \\ Environment}

\section{Accepted}

Maret 202I

\begin{abstract}
Abstrak
Kegiatan konservasi dapat berjalan dengan baik jika mampu mengakomodasikan kepentingan ekonomi masyarakat setempat, salah satunya melalui kegiatan ekowisata. Penelitian ini akan melakukan pengukuran tentang seberapa besar potensi serta peluang Hutan Desa Tangkahen di Kecamatan Banama Tingang Kabupaten Pulang Pisau. Metode yang digunakan adalah metode survei dan parameter pengukuran potensi yang digunakan adalah akses, daya dukung/sumber daya, fasilitas pendukung, interaksi sosial serta tingkat pengetahuan/ketrampilan masyarakat. Sampel dipilih dari semua pengunjung yang dapat ditemukan selama periode September - Oktober 2020. Hasil penelitian menunjukkan bahwa Hutan Desa Tangkahen (HDT) mempunyai daya tampung 134 orang per hari dan dapat bertambah jika fasilitas jalur penjelajahan di tambah sementara penilaian potensi HDT termasuk kategori sedang dengan nilai $62.58 \mathrm{I}$.
\end{abstract}

\section{Published}

April 2021 This is Open Access article under the CC-BY-SA License (http://creativecommons.org/licenses/by-sa/4.0/).
}

\section{Pendahuluan}

Upaya konservasi sumberdaya alam dalam perspektif terbaru harus dipadukan dengan pembangunan ekonomi dan sosial budaya. Di Indonesia, khususnya di Provinsi Kalimantan Tengah, dimensi tersebut perlu ditambah dengan kepastian hukum dalam kepemilikan lahan. Banyak perijinan untuk PBS terkena lahan milik masyarakat. Bahkan ada desa (misalnya Desa Tehang wilayah Kabupaten Gunung Mas) yang seluruhnya masuk kawasan hutan serta menjadi wilayah kerja KPH (Kawasan Pengelolaan Hutan).

Pemerintah sudah melakukan berbagai perbaikan terhadap tumpang tindih pengelolaan. Salah satu diantaranya melalui penerbitan kawasan hutan kemasyarakatan dan Kawasan Hutan Desa. Salah satu ijin pengelolaan yang sudah diterbitkan oleh Pemerintah c.q. Kementerian Kehutanan dan Lingkungan Hidup adalah Kawasan Hutan Desa Tangkahen di Kecamatan Banama Tingang Kabupaten Pulang Pisau Provinsi Kalimantan Tengah (selanjutnya disebut Hutan Desa Tangkahen). Berdasarkan studi di Honduras, Philipina and Bangladesh, ditemukan bahwa kunci keberhasilan konservasi dapat tetap berjalan adalah panen yang berkelanjutan (Nygren, et. al., 2006; Mukul et. al., 2010). Dalam konteks ini, maka pengelolaan Hutan Desa Tangkahen diharapkan bisa memberikan manfaat ekonomi bagi masyarakat agar nilai konservasi tetap terjaga. 
Salah satu pengelolaan hutan yang diyakini baik oleh para pakar pembangunan maupun konservasi mampu memberikan manfaat ekonomi, budaya dan sosial secara berkelanjutan adalah pengembangan eco-tourism. Ecotourism (ekowisata) adalah salah satu bentuk penerapan konsep pembangunan yang berkelanjutan (sustainable development). Ecotourism merupakan usaha untuk melestarikan kawasan yang perlu dilindungi dengan memberikan peluang ekonomi kepada masyarakat yang ada disekitarnya.

Rumusan Ekowisata pertama kali dikemukan oleh dikemukakan oleh Hector Ceballos-Lascurain pada tahun I 987 yaitu sebagai berikut :

"Nature or ecotourism can be defined as tourism that consist in travelling to relatively undisturbed or uncontaminated natural areas with the specific objectives of studying, admiring, and enjoying the scenery and its wild plantas and animals, as well as any existing cultural manifestations (both past and present) found in the areas" (Wisata alam atau ekowisata adalah perjalanan ketempat-tempat alami yang relatif masih belum terganggu atau terkontaminasi (tercemari) dengan tujuan untuk mempelajari, mengagumi dan menikmati pemandangan, tumbuh-tumbuhan dan satwa liar, serta bentuk-bentuk manifestasi budaya masyarakat yang ada, baik dari masa lampau maupun masa kini) (dikutip dari Priono, 20I2).

Kemudian pada awal tahun 1990 disempurnakan oleh The International Ecotourism Society (TIES) yaitu sebagai berikut: "Ecotourism is responsible travel to natural areas which conserved the environment and improves the welfare of local people." (Ekowisata adalah perjalanan yang bertanggung jawab ketempat-tempat yang alami dengan menjaga kelestarian lingkungan dan meningkatkan kesejahteraan penduduk setempat). Fennell (1999) mendefinisikan ekowisata sebagai bentuk berkelanjutan berbasis sumber daya alam pariwisata yang berfokus terutama pada mengalami dan belajar tentang alam, dan yang berhasil etis dampak rendah, nonkonsumtif dan berorientasi lokal (kontrol, manfaat dan keuntungan dan skala) (dikutip dari Priono, 2012).

Secara konsepsual, ekowisata merupakan suatu konsep pengembangan pariwisata berkelanjutan yang bertujuan untuk mendukung upaya-upaya pelestarian lingkungan (alam dan budaya), meningkatkan partisipasi masyarakat dalam pengelolaan serta memberikan manfaat ekonomi kepada masyarakat. Ekowisata menekankan pada prinsip konservasi, prinsip partisipasi masyarakat, prinsip ekonomi, prinsip edukasi dan prinsip wisata. Kelima prinsip tersebut berjalan bersama dan terintergrasi (Soedigdo dan Priono, 20I3).

Selaras dengan pengertian tersebut, Latupapua (20II), menyebutkan bahwa ada beberapa syarat yang harus dipenuhi oleh atraksi wisata alam agar bisa di katakan sebagai ekowisata yaitu (I) Memperhatikan daya dukung alam dan budaya lokal; (2) Membantu pelestarian alam dan ekonomi masyarakat lokal; (3) Dilaksanakan pada skala terbatas sesuai berbagai tuntutan mutu dan perilaku terhadap penyelenggaraan maupun pengunjung; dan (4) Meningkatkan pemahaman pengunjung terhadap ekologi, budaya local dan development problem. 
Berkenaan dengan hal tersebut maka perlu dilakukan penelitian dan pengukuran tentang seberapa besar potensi serta peluang Hutan Desa Tangkahen sebagai salah satu lokasi ekowisata di Propinsi Kalimantan Tengah

\section{Metode}

Penelitian ini merupakan penelitian survei dengan kuisioner sebagai alat pengumpulan data. Sampel penelitian diambil dari semua pengunjung pada bulan September - Oktober 2020. Periode tersebut dipilih karena sejak bulan September, kawasan HDT baru dibuka kembali setelah Pandemi Covid 19 dan bulan Oktober adalah periode terakhir pengumpulan data.

Data dikumpulkan dengan penyebaran angket. Angket penelitian dikembangkan dari penelitian Hastari (2005) dengan beberapa modifikasi digunakan dalam rangka mendapatkan data primer terkait dengan karakteristik pengunjung kawasan HDT. Selanjutnya penilaian potensi ekowisata kawasan HDT diperoleh dari lembar pengamatan yang memuat daftar penilaian potensi obyek daya tarik wisata alam (ODTWA) yang disusun oleh Direktorat Jenderal Perlindungan Hutan dan Konservasi Alam/Ditjen PHKA (2003) yang dikutip oleh Purwanto (20I4).

- Sedangkan validitas data menggunakan triangulasi sumber, Triangulasi sumber yang dilakukan dalam penelitian ini adalah dengan membandingkan hasil pengamatan dengan hasil wawancara, kemudian membandingkan hasil wawancara dengan dokumen yang terkait dengan tema penelitian, sehingga dengan mengunakan triangulasi sumber ini akan mengarahkan peneliti dalam mengumpulkan data wajib untuk mengunakan beragam sumber data yang tersedia. Adapun data sekunder diperoleh dari pengelola HDT, instansi teknis terkait seperti Badan Pusat Statistik (BPS), Dinas Kehutanan dan Dinas Pariwisata Provinsi Kalimantan Tengah, ataupun sumber pendukung penting lainnya.

Potensi dan peluang ekowisata HDT dihitung dengan metode penskoran dan pembobotan terhadap indikator-indikator yang digunakan untuk mendapatkan penilaian kemudian direkapitulasi. Hasil rekapitulasi penilaian dapat digunakan untuk menentukan unsur-unsur dan sub-subunsur yang ada telah maksimal atau perlu ditingkatkan kembali. Hasil ini dapat digunakan sebagai bahan rekomendasi dalam pengelolaan obyek dan daya tarik wisata (Purwanto, 2014). Penilaian yang digunakan dalam analisis data adalah modus rekapitulasi penilaian dari para narasumber.

Daya dukung ekowista dihitung berdasarkan jumlah maksimal wisatawan yang dapat ditampung di kawasan ekowisata pada waktu tertentu tanpa menimbulkan dampak negatif bagi lingkungan hidup dan wisatawan. Potensi ekologis maksimum pengunjung $(K)$ ditentukan oleh kondisi sumber daya dan jenis kegiatan yang akan dikembangkan. Panjang dan luas waktu wilayah yang dapat digunakan oleh pengunjung dipertimbangkan dengan kemampuan alam menampung wisatawan tanpa mengganggu 
kelestarian (Yulianda dkk., 2010 cit Muflih dkk., 20I5).

$$
D D K=K\left(\frac{L_{p}}{L_{t}}\right)\left(\frac{W_{t}}{W_{p}}\right)
$$

Dimana : DDK : Daya dukung kawasan (wisatawan); $K$ : potensi ekologis maksimum pengunjung persatuan unit area (satu wisatawan per 50 meter); $L_{p}$ : panjang area yang dapat dimanfaatkan wisatawan (meter); $L_{t}$ : Unit area untuk kategori tertentu (meter); $W_{t} \quad$ : waktu yang disediakan oleh kawasan untuk kegiatan wisata dalam satu hari (jam); dan Wp : waktu yang dihabiskan oleh pengunjung untuk setiap kegiatan tertentu (jam).

\section{Hasil Penelitian}

Karakteristik Biofisik Hutan Desa

\section{Tangkahen}

Hutan Desa Tangkahen awalnya merupakan lahan perhutanan social, Lokasi perhutanan social pada awalnya seluas 2.000 ha. Sebagian kawasan perhutanan social tersebut (I60 ha) kemudian diusulkan menjadi hutan desa pada tahun 2014 dan telah ditetapkan melalui Keputusan Menteri Lingkungan Hidup dan Kehutanan ditetapkan menjadi hutan desa. Pada saat ini, hutan desa Tangkahen dikelola oleh Tim Pengelola Hutan Desa (TPHD) Tangkahen yang dipimpin oleh Masimpei. TPHD Tangkahen sampai saat ini lebih banyak melakukan pemeliharaan tanaman yang ada dan belum banyak melakukan pengkayaan. Tampilan fisik hutan desa Tangkahen sendiri merupakan hutan sekunder dengan potensi jenis dan kerapatan yang cukup baik. Saat ini kawasan telah ditumbuhi dengan berbagai jenis pohon khas tropika basah dengan ketinggian mencapai lebih dari 25 meter dan diameter batang ada yang mencapai $50 \mathrm{~cm}$.

Struktur vegetasi hutan desa Tangkahen adalah ciri khas hutan tropis sekunder yang didominasi oleh galam (Melaleuca leucadendron), tumih (Cambretocarpus rotundatus), dan terentang (Campnosperma spp). Beberapa tumbuhan alami juga ada dalam jumlah kecil seperti: pasak bumi (Eurycoma longifolia), jelutung (Dyera sp), pulai (Alstonia pneumatophora), punak (Tetramerista glabra), ramin (Gonystylus bancanus), belangeran (Shorea balangeran), meranti (Shorea pauciflora), malam-malam (Diospyros malam), pasir-pasir (Urandra secundiflora), pisang-pisang (Mezzeatia parvifolia), nyatoh (palaquium cochreari), jambujambu (Eugenia spp), dan bintangur (Calophyllum kunstleri).

\section{Karakteristik Pengunjung Hutan Desa Tangkahen}

Pengunjung Hutan Desa Tangkahen (HDT) didominasi oleh kaum laki-laki (>50\%) dan lebih dari tiga perempat pengunjung HDT memiliki status belum menikah. Mayoritas pengunjung HDT adalah dewasa muda dengan usia 21-30 tahun (>50\%). Pengunjung HDT umumnya merupakan mahasiswa yang baru selesai dari pendidikan lanjutan tingkat atas (>70\%). Pengunjung dengan pendidikan sarjana menempati porsi sebanyak $30 \%$ dari total pengunjung HDT. Umumnya mereka adalah mahasiswa (>70\%) yang lebih dari separonya belum memiliki pendapatan tetap sendiri dan berpendapatan kurang dari satu juta rupiah. Selama kurun waktu tersebut, HDT hanya dikunjungi oleh wisatawan domestik (Tabel I.).

Pengunjung HDT dilakukan secara rombongan (>90\%) dengan lama kunjungan berkisar dua sampai empat jam. Umumnya mereka berkunjung untuk kali pertama. Bentuk kunjungan secara rombongan menyebabkan mereka tidak melakukan belanja di HDT < Rp. 200.000 (>25\%). Informasi tentang HDT didominasi dari informasi yang bersumber dari teman/kolega ( $>50 \%$ ). Posisi kedua, informasi tentang HDT diperoleh dari sekolah atau universitas (>10\%). Hal ini dimungkinkan karena kunjungan ke HDT biasanya terkait dengan 
Yos A. Tangkasiang dan Kristanto.V.Baddak. Studi Potensi dan Peluang Ekowisata di Hutan Desa Tangkahen Kecamatan Banama Tingang Kabupaten Pulang Pisau

kegiatan praktikum ataupun hal- hal yang hidup.

berhubungan dengan pendidikan lingkungan

Tabel I. Karakteristik Pengunjung Hutan Desa Tangkahen

\section{Variabel}

I. Jenis Kelamin

- Laki-laki

- Perempuan

2, Status Pernikahan

- Menikah

- Belum Menikah

3, Kelompok Usia

- $\quad 12-20$ tahun

- $\quad 21-30$ tahun

- $\quad 31$ - 40 tahun

- >40 tahun

4. Asal

- Dalam Negeri

- Luar Negeri

5. Pendidikan

- SLTA

- Diploma

- Sarjana

- Pasca Sarjana

6. Pekerjaan

- Mahasiswa

- PNS

- Pegawai Swasta

- Wiraswasta

- Guru/Dosen

- Lainnya

7. Pendapatan

- Tidak ada

$-\quad<$ I juta

- I - 3 juta

- $\quad 3-5$ juta

\section{Frekuensi}

26

23

36

73,47

13

26,53

5

10,20

16

32,65

10

20,41

18

36.74

60

100,0

0

0,00

18

36,74

3

0

6,12

0,00

28

57,14

14

28,57

0

0,00

0

0.00

4

8,16

28

57,14

2

4,08

4

8,16

4

8,16

14

28,57

27

55,11 
Tabel 1. Lanjutan

\section{Variabel}

8. Bentuk Kunjungan

- Teman

- Rombongan Wisata

- Sekolah

9. Lama Kunjungan

$-\quad<2$ jam

- 2-4 jam

- 4-6 jam

10. Frekuensi Kunjungan

- Pertama kali

- Lebih dari sekali

II. Pengeluaran Kunjungan

- Tidak ada

- $<200.000$

- $\quad 200.000-600.000$

12. Informasi tentang HDT

- Internet

- Sosial Media

- Teman/Kolega

- Brosur/Leaflet

- Papan Nama

- Sekolah/Universitas

\section{Frekuensi}

$\%$

$\begin{array}{cc}2 & 4,08 \\ 46 & 93,88 \\ 1 & 2,04\end{array}$

0

0.00

10

20,4I

39

79,59

43

87.76

6

12,24

$\begin{array}{cc}0 & 0,00 \\ 48 & 97,96 \\ 1 & 2,04\end{array}$

\section{Daya Dukung Kawasan Jumpun Pambelom}

Ekowisata HDT merupakan kawasan wisata dengan bentuk jalur untuk tracking sepanjang 546,85 m. Namun HDT juga dilengkapi dengan kawasan pendukung berupa Hutan Kemasyarakatan dengan jalur tracking sepanjang $1.060 \mathrm{~m}$. Jika waktu berkunjung yang jamak dihabiskan oleh pengunjung di ekowisata HDT adalah enam jam maka daya dukung kawasan (DDK) ekowisata HDT adalah 92 orang per hari. Namun pengunjung biasanya juga melakukan tracking di kawasan pendukung dan menghabiskan waktu delapan jam sehingga DDK keseluruhan sebesar 22 I orang per hari. Daya dukung kawasan HDT lebih tinggi dibandingkan dengan beberapa destinasi ekowisata sejenis (jalur/titian) (Tabel 2.)

Tabel 2. Daya dukung kawasan ekowisata HDT dengan beberapa destinasi ekowisata sejenis

\begin{tabular}{lccc}
\hline \multicolumn{1}{c}{ Lokasi Ekowisata } & Lp & Wp & DDK \\
\hline Hutan Desa Tangkahen & & & \\
a. HDT (sendiri) & 547 & 6 & 92 orang/hari \\
b. HDT plus kawasan & 1607 & 8 & 201 orang/hari \\
pendukung & & &
\end{tabular}


Yos A. Tangkasiang dan Kristanto.V.Baddak. Studi Potensi dan Peluang Ekowisata di Hutan Desa Tangkahen Kecamatan Banama Tingang Kabupaten Pulang Pisau

$\begin{array}{lccc}\text { Pasisir Tanjung Pasir I } & 1.240 \mathrm{~m} & 2 & 162 \text { orang/hari } \\ \begin{array}{l}\text { Hutan Mangrove di Pantai } \\ \text { Sari Ringgung 2 }\end{array} & 1.566 \mathrm{~m} & 3,4 & 87 \text { orang/hari } \\ \begin{array}{l}\text { Hutan Jumpun Pambelum } \\ \text { Tumbang Nusa }\end{array} & 604 \mathrm{~m} & 4 & 134 \text { orang/hari }\end{array}$

Keterangan : 'Tangerang (Muflih et al., 20I5); ${ }^{2}$ Pesawar-Lampung (Sari et al., 20I5); Anshauri et.al., 2017)

\section{Potensi Ekowisata Hutan Desa Tangkahen}

Penilaian potensi ODTWA ekowisata HDT menggunakan pedoman ODTWA yang dikembangkan oleh Dirjen PHKA (2003). Kriteria yang dipakai sebagai dasar penilaian potensi ekowisata HDT meliputi: daya tarik obyek wisata; aksebilitas; kondisi masyarakat sekitar; elemen institusi; potensi pasar; akomodasi; pengelolaan dan pelayanan; iklim; keamanan; sarana dan prasarana wisata; ketersediaan air bersih; hubungan dengan obyek wisata sekitar; penurunan kualitas lingkungan; daya dukung kawasan; dan pangsa pasar. Hasil klasifikasi penilaian potensi ODTWA ekowisata HDT disajikan pada Tabel 3. yang merupakan indeks dari hasil penilaian tiap-tiap kriteria tersebut diatas.

Berdasarkan hasil penilaian kriteria dapat diketahui bahwa ekowisata HDT memiliki Tabel 3. Hasil penilaian potensi Hutan Desa Tangkahen. potensi ODTWA dalam kategori sedang (skor 65,772). Namun demikian, ekowisata HDT memiliki potensi dan layak untuk dikembangkan. Ekowisata HDT dapat dikembangkan dengan persyaratan tertentu yang memerlukan perhatian dan pembenahan lebih lanjut berdasarkan hasil penilaian ODTWA. Beberapa kriteria yang memiliki nilai rendah seperti daya tarik obyek wisata, kondisi masyarakat sekitar, elemen institusi, potensi pasar, sarana dan prasarana wisata serta hubungan dengan obyek wisata lain disekitarnya. Unsur-unsur tersebut masih memerlukan perhatian lebih lanjut untuk dikembangkan menjadi destinasi ekowisata yang unggul. Sementara kriteria yang memiliki nilai tinggi antara lain aksesibilitas, akomodasi, pengelolaan dan pelayanan, iklim, ketersediaan air bersih, kualitas lingkungan dan daya dukung kawasan. Komponen ini terus dipertahankan sebagai unggulan di HDT.

\begin{tabular}{lcccc}
\hline \multicolumn{1}{c}{ Kriteria } & $\begin{array}{c}\text { Nilai } \\
\text { Maksimal } \\
\text { Pontensi } \\
\text { ODTWA }\end{array}$ & $\begin{array}{c}\text { Nilai } \\
\text { Potensi } \\
\text { ODTWA }\end{array}$ & $\begin{array}{c}\text { Indeks } \\
\text { Nilai } \\
\text { Potensi } \\
(\%)\end{array}$ & $\begin{array}{c}\text { Klasifikasi } \\
\text { Potensi } \\
\text { ODTWA }\end{array}$ \\
\hline Daya tarik obyek wisata & 1440 & 610 & 42.36 & Rendah \\
Aksebilitas & 850 & 700 & 82.35 & Tinggi \\
Kondisi masyarakat sekitar & 1200 & 550 & 45,83 & Rendah \\
Elemen institusi & 1800 & 850 & 47,22 & Rendah \\
Potensi pasar & 950 & 460 & 48,42 & Rendah \\
Akomodasi & 90 & 80 & 88,89 & Tinggi \\
Pengelolaan dan Pelayanan & 360 & 300 & 83,33 & Tinggi \\
Iklim & 480 & 420 & 87,50 & Tinggi \\
Keamanan & 150 & 110 & 73,33 & Sedang
\end{tabular}




\begin{tabular}{lcccc} 
Sarana dan prasarana wisata & 450 & 210 & 43,36 & Rendah \\
Ketersediaan air bersih & 720 & 700 & 98,59 & Tinggi \\
$\begin{array}{l}\text { Hubungan dengan obyek } \\
\text { Wisata di sekitarnya }\end{array}$ & 100 & 40 & 40,00 & Rendah \\
Penurunan kualitas lingkungan & 180 & 145 & 80,56 & Tinggi \\
Daya dukung kawasan & 450 & 390 & 86,67 & Tinggi \\
Pangsa pasar & 270 & 210 & 77,77 & Sedang \\
\hline
\end{tabular}

Sumber : Analisis Data Primer

\section{Pembahasan}

Karakteristik pengunjung. Ekowisata HDT saat penelitian ini dilakukan didominasi oleh pengunjung berjenis kelamin laki-laki meskipun selisihnya tidak terlalu jauh. Hasil ini sesuai dengan penelitian sejenis (Hastari, 2005; Deni, 2010; Purnomo, 20I3; Utari, 20I4) bahwa lakilaki lebih menyukai wisata alam. Namun, secara umum laki-laki dan perempuan memiliki kebutuhan berwisata yang sama (Pramono \& Kunarso, 2008). Lebih lanjut, pengunjung ekowisata HDT didominasi oleh wisatawan yang berusia dewasa (di atas 21 tahun). Hal ini sesuai pendapat Purnomo (2013) yang menyatakan bahwa pengunjung wisata alam umumnya didominasi oleh kaum dewasa yang memerlukan suasana baru yang lebih menantang. Kunjungan wisatawan dewasa ke destinasi wisata alam dalam rangka berpetualang, mencari tantangan, motivasi fisik, serta alasan pendidikan dan penelitian. Keberadaan destinasi wisata baru menjadi daya tarik wisatawan berkunjung. Keberadaan yang dekat dengan Kota Palangka Raya menjadi pertimbangan lain dalam memilih ekowisata HDT sebagai destinasi. Wisatawan cenderung melakukan perjalan wisata pada destinasidestinasi wisata terdekat dengan aksesibilitas mudah.

Adapun pengunjung ekowisata HDT umumnya adalah dosen dan mahasiswa. Hasil sigi ini berbeda dengan sigi yang dilakukan di Arboretum Nyaru Menteng (Hastari, 2005), Pulau Sempu (Purnomo, 20I3), Kebun Raya
Cibodas (Utari, 2014) dan Jumpun Pambelum Tumbang Nusa (Anshauri et. al., 2017),. yang menyatakan bahwa pengunjung di kedua destinasi didominasi oleh pelajar/mahasiswa. Mereka melakukan kunjungan secara berombongan. Hal ini sesuai dengan pendapat Hastari (2005) dan Purnomo (20I3) yang menyatakan bahwa bentuk kunjungan yang umum pada destinasi wisata alam adalah kedatangan berombongan. Kunjungan berombongan yang dilakukan oleh wisatawan berstatus dosen/mahasiswa dilakukan dalam rangka mengekplorasi diri dengan melakukan perjalanan, praktikum dan penelitian di destinasi wisata alam (Sari et al., 20I5). Kunjungan para dosen dan mahasiswa ini menkonfirmasi bahwa HDT masih sering digunakan untuk kegiatan penelitian dan belum sepenuhnya dianggap sebagai lokasi wisata.

Pendidikan yang tinggi meningkatkan pemahaman mereka tentang konservasi sehingga mereka berminat untuk menikmati kepariwisataan alam (Purnomo, 20l3). Hal ini didukung dengan fakta di lapangan bahwa mereka melakukan kunjungan untuk kali pertama dalam rangka perkuliahan dan kegiatan konservasi. Kegiatan ekowisata utamanya diperuntukan untuk kegiatan penelitian, pendidikan, konservasi, serta penjelajahan dan petualangan (Kurniawati, 20I2).

Wisatawan muda umumnya merupakan wisatawan yang tidak loyal dan memiliki rasa penasaran kepada sesuatu yang baru. Hal ini dibuktikan dengan kunjungan mereka ke 
ekowisata HDT didominasi oleh pengunjung dengan status kunjungan pertama kali. Informasi yang diperoleh hanya dari teman/kolega semakin memperkuat dugaan ini.

Daya dukung kawasan. Daya dukung berkaitan dengan tingkat kunjungan dan kegiatan pengunjung (Sari et al., 20I5) sehingga perlu diperhatikan agar dalam pengelolaan ekowisata sesuai dengan batas-batas yang dapat diterima. Perhitungan daya dukung dapat digunakan untuk mencegah kerusakan kawasan obyek yang disebabkan oleh kunjungan pengunjung yang berlebihan (Purnomo, 20l3). Daya dukung juga menentukan kenyaman dan kepuasan pengunjung dalam menikmati aktivitas wisata di area yang dikunjungi.

Ekowisata HDT harus memperhatikan daya dukung kawasan agar tidak menimbulkan kerusakan lingkungan akibat kunjungan wisatawan yang berlebihan. Adapun aspek-aspek yang perlu diperhatikan dalam pengembangan HDT yaitu kondisi lingkungan fisik, biologi, sosial dan psikologis untuk mendukung aktivitas pengunjung tanpa mengurangi kualitas lingkungan dan kepuasan pengunjung (Muflih et al., 20I5).

Kemampuan daya dukung HDT dengan panjang jalur 546,85 m. Namun HDT juga dilengkapi dengan kawasan pendukung berupa Hutan Kemasyarakatan dengan jalur tracking sepanjang $1.060 \mathrm{~m}$. Jika waktu berkunjung yang jamak dihabiskan oleh pengunjung di ekowisata HDT adalah enam jam maka daya dukung kawasan (DDK) ekowisata HDT adalah 92 orang per hari. Namun pengunjung biasanya juga melakukan tracking di kawasan pendukung dan menghabiskan waktu delapan jam sehingga DDK keseluruhan sebesar 22I orang per hari. Apabila melebihi daya dukung kawasan maka dapat menimbulkan ancaman besar bagi ekosistemnya (Sari et al., 2015). Berdasarkan hasil wawancara dengan pengelola, diketahui rata-rata jumlah kunjungan per minggu sebesar 5 - 10 orang. Akan tetapi untuk hari tertentu jumlah pengunjung bisa mencapai 30 orang dalam sekali kunjungan saja. $\mathrm{Hal}$ ini belum menimbulkan masalah bagi ekosistem di HDT. Namun demikian, untuk menarik wisatawan perlu adanya penambahan nilai daya dukung kawasan misalnya dengan memperpanjang jalur (Sari et al., 20I5), melakukan budidaya anggrek hutan, menambah fasilitas rumah pohon atau membuat lokasi pemandian di danau yang terletak di HDT.

Potensi ekowisata. Ekowisata HDT memiliki ekosistem hutan sekunder yang masih bagus. Di samping itu, eksesibilitas yang tinggi, keberadaan akomodasi pendukung kegiatan wisata yang lengkap, keamanan yang terjaga, daya dukung kawasan yang masih baik, dan ketersediaan air bersih yang memadai menjadi daya faktor-faktor pendukung ekowisata HDT untuk dikembangkan lebih lanjut. Meskipun daya tarik obyek wisatanya rendah tetapi kealamian ekosistemnya dapat menjadi daya tarik ekowisata HDT. Kondisi ini selaras dengan temuan Kurniawati (20/2) mengungkap bahwa tingkat kealamian ekosistem gambut merupakan salah satu daya tarik pengunjung untuk berwisata di Ekowisata Gambut Baning di Sintang.

Komponen daya tarik wisata yang rendah dari ekowisata HDT dapat ditingkatkan dengan penambahan fasilitas wisata alam di sana. Fasilitasfasiltas tersebut antara lain: I) Jalur tracking yang dilengkapi dengan fasilitas interpretasi, seperti papan intepretasi, papan penunjuk arah, dan naungan/gazebo (Kurniawati, 2012; Sari et al., 20I5); 2) Pembuatan menara pengamatan burung (Sari et al., 2015); 3) fasilitas lain seperti: bangunan pusat informasi, persemaian tanaman hutan gambut, kios cinderamata, dan kios makanan (Kurniawati, 20I2); 4) kegiatan outbond (Deni, 20I0); 5) fotografi (Purnomo, 20I3); 6) pemandu wisata (Kurniawati, 2012; Sari et al., 20I5); 7) paket pembelajaran lingkungan hidup yang menarik (Afra et al., 2008; Purnomo, 20I3), khususnya pengetahuan tentang ekosistem gambut; 8) fasilitas toilet dan tempat ibadah (Afra 
et al., 2008; Deni, 20 I0).

Elemen institusi ekowisata HDT yang rendah dapat ditingkatkan dengan pembangunan jejaring kerjasama yang melibatkan semau pemangku kepentingan ekowisata HDT seperti ekowisatawan, masyarakat setempat, pelaku usaha, lembaga swadaya masyarakat, dan pemerintah (Purnomo, 20I3). Sedangkan potensi pasar yang rendah dapat dioptimalkan dengan peningkatanpromosi tentang ekowisata HDT dan kerjasama para pemangku kepenitingan. Perlindungan dan penjagaan kawasan dapat dilakukan untuk meningkatkan keamanan kawasan dari bahaya kebakaran lahan. Potensi ancaman keamanan terbesar dari ekowisata HDT adalah resiko kebakaran lahan yang seringkali terjadi. Pengendalian kebakaran hutan selain untuk perlindungan kawasan juga dapat dijadikan sebagai wahana edukasi kepada ekowisatawan yang berkunjung ke HDT.

\section{Kesimpulan}

Pengunjung ekowisata HDT umumnya adalah pengunjung dengan tujuan khusus, terkait pendidikan lingkungan hidup dan pengelolaan hutan tropis, seperti dosen atau mahasiswa. Mereka melakukan kunjungan secara berombongan dengan durasi enam sampai delapan jam. Informasi tentang HDT diperoleh dari sekolah/kampus dan teman/kolega. Ekowisata HDT memiliki potensi untuk dikembangkan menjadi destinasi baru ekowisata di Kalimantan Tengah. Namun demikian perlu dilakukan peningkatan atraksi/daya tarik wisata di sana. Jenis atraksi yang dapat dikembangkan antara lain: pengembangan rute penjelajahan, gazebo, menara pengamatan burung (birds watching), paket pembelajaran lingkungan hidup, pengkayaan tanaman (misalnya tanaman anggrek), pemandian alam dan fasilitas outbond. Di samping itu, pengelola Ekowisata HDT melakukan promosi yang lebih intensif tentang daya tarik ekowisata HDT.
Namun demikian, pengembangan atraksi wisata di ekowisata HDT tetap harus memperhatikan DDK karena ekowisata HDT saat ini hanya dapat menampung pengunjung sebanyak 92 orang per hari atau 201 orang/hari jika kawasan pendukung diperhitungkan. Penambahan atraksi ditujukan untuk mendistribusikan pengunjung baik secara spatial ataupun waktu.

\section{Ucapan Terima Kasih}

Peneliti menyampaikan penghargaan dan terima kasih kepada Kemenristek/BRIN yang telah mendanai penelitian ini. Penghargaan dan terima kasih juga ditujukan kepada Tim Pengelola Hutan Desa (TPHD) Tangkahen yang dipimpin oleh Bapak Masimpei yang telah bekerja sama dengan baik mendukung penelitian ini.

\section{Daftar Pustaka}

Afra D, Makalew N, Damayanti VD, Hadi AA. 2008. Rencana penataan lansakap Gunung Kapur Cibadak untuk ekowisata di Kecamatan Ciampea Kabupaten Bogor. Jurnal Ilmu Pertanian Indonesia I3(3): I82-193.

Deni. 2010. Kajian Awal terhadap Potensi Taman Burung Masigit Kareumbi Jawa Barat untuk Pengembangan Ekowisata. Jurnal Ilmiah Kehutanan. Vol. 4 (I): I-I I.

Direktorat Jenderal Perlindungan Hutan dan Konservasi Alam (Ditjen PHKA). 2003. Pedoman Analisis Daerah Operasi Obyek dan Daya Tarik Wisata. Ditjen PHKA, Bogor.

Effendi TN, dan Sujali. 1989. Pengembangan kepariwisataan: sebuah pendekatan geografi. Majalah Geografi Indonesia 2(3): I-9.

Hastari B. 2005. Karakteristik obyek wisata dan persepsi masyarakat sebagai dasar dalam pengembangan wisata alam studi kasus: Arboretum Nyaru Menteng Palangka Raya. [Tesis]. SPS IPB, Bogor.

Kurniawati H. 20I2. Perencanaan lanskap kawasan ekowisata gambut Baning di Kota Sintang Kalimantan Barat. [Tesis]. SPS IPB, 
Bogor.

Latupapua, Y.T. 20II. "Persepsi Masyarakat terhadap Potensi Obyek Daya Tarik Wisata Pantai di Kecamatan Kei Kecil Kabupaten Maluku Tenggara" Jurnal Agroforestri VI (2) : 92 $-102$

Muflih A, Fahrudin A, Wardianto Y. 2015. Kesesuaian dan daya dukung wisata pesisir Tanjung Pasir dan Pulau Untung Jawa. Jurnal IImu Pertanian Indonesia 20(2): 141-149.

Mukul, S.A., M.B. Uddin, A.Z.M.M. Rashid and J. Fox. 20I0. Integrating Livelihoods and conservation in Protected Areas : Understanding the Role and Stakeholder views on Prospect for Non-Timber Forest Product, a Bangladesh Case Study" International Journal of Sustainable Development \& World Ecology. 17 (2) : $180-188$

Nygren, A., C.L. Richman, K. Keinanen and L. Asta. 2006. "Ecological, Socio-Cultural, Economics and Political Factors Influencing the Contribution of Non-Timber Forest Product to Local Livelihood: Case Studies from Honduras and the Phillipines" Small-scale Forest Econmics, Management and Policy. 5 (2) : 249 - 269.

Pramono, B.T., dan Kunarso, A. 2008. Pengaruh perilaku pengunjung terhadap jumlah Kunjungan di Taman Wisata Alam Punti kayu Palembang. Jurnal Penelitian Hutan dan Konservasi Alam 5(5): 423-433.

Priono, Y. 2012. "Pengembangan Kawasan Ekowisata Bukit Tangkiling Berbasis Masyarakat" Jurnal Perspektif Arsitektur. 7 (I) : 5 I $-67$.

Purnomo H. 2013. Kajian potensi dan daya dukung ekowisata di kawasan Cagar Alam Pulau Semou Jawa Timur [Tesis]. SPS IPB, Bogor.

Purwanto S. 20I4. "Kajian potensi dan daya dukung Taman Wisata Alam Bukit Kelam untuk strategi pengembangan ekowisata". [Tesis]. SPS IPB, Bogor.

Sari Y, Yuwono SB, Rusita. 2015. Analisis potensi dan daya dukung sepanjang jalur ekowisata hutan mangrove di pantai Sari Ringgung, Kabupaten Pesawaran, Lampung. Jurnal Sylva Lestari. 3(3): 3 I-40.

Soedigdo, D. dan Y. Priono. 20/3. "Peran Ekowisata dalam Pengembangan Pariwisata Berbasis Masyarakat pada Taman Wisata Alam (TWA) Bukit Tangkiling Kalimantan Tengah" Jurnal Perspektif Arsitektur. 8 (2) : I - 8.

Utari WD. 2014. Daya Dukung ekologis dan psikologis ekowisata di Kebun Raya Cibodas. [Tesis]. SPS IPB, Bogor. 